\title{
A cultura colaborativa e a criativida- de destrutiva da web 2.0: aplicativos para o ensino da medicina
}

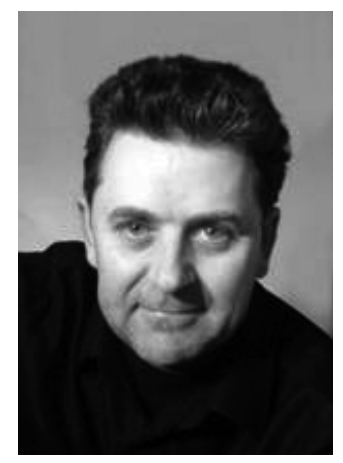

\author{
Steven Wheeler \\ Faculty of Education, \\ University of Plymouth, \\ Plymouth, Reino Unido \\ s.Wheeler@plymouth. \\ ac.uk
}

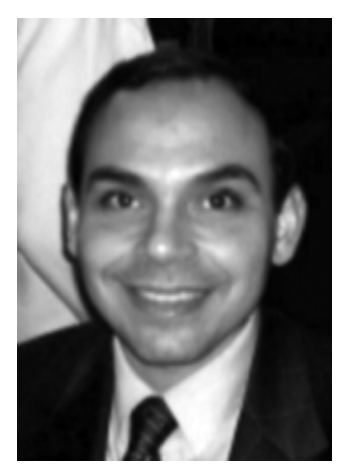

Maged Kamel Boulos

Faculty of Health \& Social Work, University of Plymouth, Plymouth, Reino Unido maged.kamelboulos@ plymouth.ac.uk

\section{Resumo}

Examinamos o recente crescimento do software ${ }^{1}$ interativo (Web 2.0), seu primeiro impacto no ensino, e apresentamos uma análise de algumas pesquisas, conduzidas nos últimos tempos, que avaliam suas aplicações pedagógicas. Salientamos a tendência dos estudantes a serem criativos e destrutivos ao utilizarem softwares interativos, particularmente wikis ${ }^{2}$, web $\operatorname{logs}\left(b \log s^{3}\right)$ e outros ambientes de rede baseados em textos. As atividades dos estudantes nesses ambientes de softwares interativos podem causar tensão e conflito, e as reações variam mas, em geral, os resultados têm sido positivos. Alguns exemplos do ensino da medicina são analisados, oferecendo ao leitor exemplos da utilização de softwares interativos que têm sido usados em contextos do ensino de medicina clínica.

\section{Palavras-chave}

Software interativo, Web 2.0, conteúdo colaborativo, espaços wiki, blogs

\section{Introdução}

O surgimento do software interativo (ou da chamada 'Web 2.0') propicia novas e estimulantes oportunidades para professores criarem meios de ensino colaborativos e comunicativos para seus estudantes. Essa personificação da World Wide Web [rede de alcance mundial, conhecida pela abreviatura www] mantém potenciais de transformação semelhantes para professores e estudantes (RICHARDSON, 2006). Mashups [combinações de aplicativos], misturas e justaposições de ferramentas digitais formam a base para um ambiente dinâmico e criativo no qual os estudantes podem aprender através de trabalhos colaborativos e coletivos baseados em pesquisas. Softwares de alimentação de novos conteúdos possibilitam que os usuários recebam avisos de atualizações de páginas da Web diretamente em seus computadores de mesa ou em aparelhos portáteis. A popularidade desses aplicativos está crescendo rapidamente, uma vez que os estudantes vêem as oportunidades de ganhar tempo e espaço de modo que o aprendizado possa ser organizado em estilos de vida de negócios.

No entanto, surgiu um dilema. Embora, por sua própria natureza, o software interativo atraia atividades que, em seu cerne, envolvem democracia e são livres de influências institucionais (RICHARDSON, 2006), essa liberdade pode ter o efeito de abrir a porta para o abuso ou para a má utilização de tecnologias. Aparentemente, elementos destrutivos podem emergir onde o direito de 
participar é explorado. Regras institucionais podem ser infringidas, causando um efeito prejudicial sobre a organização tradicional por meio da subversão de práticas previamente aceitas. Neste artigo, exploramos a natureza criativa e destrutiva da participação na Web 2.0 e suas conseqüências para a educação.

\section{Aprendizado autônomo}

Os estudantes que usam wikis e blogs geralmente trabalham, de maneira autônoma e independente, longe do alcance de qualquer autoridade reconhecida, de modo que é discutível em que medida as instituições educacionais podem e devem tentar "gerenciar" essa tecnologia de aprendizado. Acontece que algumas universidades vêem necessidade de controlar o uso desse tipo de software em contextos de aprendizados formais, mas não usam o poder de vigilância necessário para viabilizá-lo. Principalmente os estudantes mais jovens com freqüência começam a usar o software interativo para compartilhar sites favoritos, imagens e vídeos, e outros meios de comunicação fora dos auspícios ou do controle de sua instituição. Sites populares incluem Bebo, FaceBook, YouTube e MySpace, todos usados por milhões de inscritos diariamente. A regulação dessas atividades, mesmo que desejável, seria impraticável para a maioria das organizações.

\section{Wikis}

Obviamente, existe uma atração por essas páginas da rede disponíveis livremente, mas a questão é se as autoridades educacionais devem tentar controlar o poder desses aplicativos ou deixá-los expandir de uma maneira descontrolada e "viral". A noção de seleção natural - "Darwikianismo" é o termo empregado para o ciclo vital de wikis - pode ser usada como um padrão para testar a longevidade e a utilidade dos softwares interativos.

Wikis rapidamente se transformam em reservatórios de conhecimento compartilhado uma vez que o público em geral agrega suas contribuições o tempo todo (GODWIN-JONES, 2003) e a "sabedoria das massas" pode ser utilizada para a criação das "ferramentas de conhecimento". A rede interativa propicia um ambiente estimulante e criativo, em que os leitores se tornam escritores e os consumidores contribuintes (BOULOS et al., 2006). É realmente a rede em que "ler/escrever" podem ser inseparáveis.

\section{Ambientes de aprendizado "não-controlados"}

Apesar de uma orientação natural para a independência não-controlada, tutores que cuidam do ensino à distância podem ser colocados unicamente para fazer uso da capacidade e do potencial do software interativo. Os professores podem tentar criar, por exemplo, atividades que, centradas nos estudantes, envolvam e desafiem por meio da plataforma do software interativo. Essas atividades podem precisar ser ligeiramente controladas mantendo a natureza autônoma dos espaços interativos.
Tem havido um longo e incessante debate sobre a eficácia da mídia e da tecnologia no aprendizado (KOZMA, 1994; CLARK, 1994), mas a escolha da tecnologia de transmissão é crucial para o sucesso de um programa. A Web 2.0 vai além abordagem de um "ambiente de aprendizado controlado" ou MLE [na sigla em inglês], de certa maneira formal e linear, estabelecida por toda parte na maioria do ensino superior e suplementar, proporcionando uma arquitetura de participação que estimula os estudantes a entrarem em comunidades de aprendizado não-hierárquicas. Talvez a nova expressão "ambiente de aprendizado não-controlado" seja apropriada ao uso da Web 2.0 para o ensino à distância. Sem dúvida, parece que os dias de ambiente de aprendizado controlado estão contados.

Mais usual, a expressão “ambientes de aprendizado personalizado" ou PLE [na sigla em inglês] foi cunhada para descrever sistemas de arquitetura aberta nos quais os usuários criam, mesclam e editam seu próprio conteúdo. Este pode ser "tagged" ["rotulado" ou "classificado"] usando palavras-chave, de modo que outros usuários, de dentro e de fora do grupo de usuários, possam encontrar as páginas e, se permitido, participarem também da edição. Um site popular organizado com "tags" - possibilita que esses processos sejam conduzidos por indivíduos e grupos de uma maneira altamente visível e acessível. Independentemente da maneira como esse software aberto para edição é visto, fica evidente que o papel específico do professor/instrutor está sendo radicalmente reformulado, os professores tornam-se suportes enquanto os estudantes desempenham um papel mais ativo na criação e expressão do conhecimento.

\section{Presença interativa}

Estimular estudantes a mergulharem em ambientes de aprendizado altamente colaborativos nos quais eles são capazes de criar, misturar, modificar e ampliar suas próprias ferramentas de conhecimento usando softwares interativos como "instrumentos cognitivos" não é apenas desejável (JONASSEN et al., 1999). Deveria ser também um objetivo claro para todos aqueles que desejam criar uma presença interativa no ensino à distância. Indivíduos socialmente isolados, em geral, podem ser menos saudáveis do que aqueles ligados a um ambiente amplamente interativo. Putnam (2000) sugere que o capital social possibilita aos indivíduos aumentarem sua consciência das maneiras como seu destino está ligado à comunidade. "As redes que constituem capital social também servem como canais para o fluxo de informações úteis que facilitam atingir nossos objetivos." (PUTNAM, 2000). Se usado corretamente, o software interativo proporciona um ambiente de rede como esse, fornecendo aos estudantes ferramentas de comunicação e contato virtual que simula uma co-presença.

Há uma "frieza" perceptível relatada por muitos estudantes cujo aprendizado é, em grande medida, mediado pela tecnologia (WALLACE, 1999; RICE, 1993). A noção de que alguém não está simplesmente interagindo com a tecnologia, mas que o calor do contato humano 
existe na "outra extremidade" é vital para o sucesso da maioria dos aprendizes remotos (WALLACE, 1999). A presença interativa reflete a percepção do estudante de que ela/ele está se comunicando com as pessoas através da tecnologia (SHORT et al., 1976). Alcançar um efeito de presença interativa é, portanto, importante no ensino à distância pois, sem ela, os estudantes podem se sentir isolados. Com um sentido de presença interativa, por meio da intervenção tutorial direta, os estudantes sentem que não estão sozinhos em sua jornada de longa distância e freqüentemente elevam seu desempenho (BELAWATI, 2005); observam-se reações semelhantes no aprendizado das crianças (TUNG et al., 2006). A comunicação pessoal, rapidez de respostas do tutor e do grupo de colegas, e um sentimento de objetivo comum em uma comunidade de aprendizado são características que contribuem significativamente para sentimentos mais fortes de presença interativa (WHEELER, 2006). A web interativa tem a possibilidade de oferecer essas características.

\section{Divisão de trabalho}

Uma das características de wikis e de outras comunidades baseadas em softwares de edição coletiva, como o Google Textos e Planilhas, é que todos os membros de uma comunidade ou grupo de usários podem modificar, ampliar ou apagar as anotações anteriores com rapidez (RICHARDSON, 2006). Essas atividades, embora aparentemente destrutivas, tendem a proporcionar maior clareza do pensamento, correção cuidadosa de erros, e elaboração mais compreensível das idéias e do conteúdo atualizados anteriormente. A divisão de trabalho requerida para engajar um grupo inteiro de estudantes na produção de conteúdo pode ser explicada com base na estrutura da teoria da atividade (ENGESTRÖM, 1993). A divisão de trabalho, nesse contexto, diz respeito à relação horizontal entre membros de uma comunidade de aprendizado como resultado de suas ações mútuas e interações. Wikis podem subverter valores tradicionais como os de autoria individual e de propriedade intelectual (RICHARDSON, 2006), enquanto a autoria do conteúdo da comunidade se torna um fator de equalização. Uma divisão vertical de "poder e status" que representa esse diferencial também pode estar presente (THORNE, 2000). Se uma divisão como essa não for resolvida na comunidade de aprendizes, surgem conflitos.

Por isso editores e organizadores de espaços de elaboração abertos regulam cuidadosamente a produção de conteúdo, exercendo o poder de remover a inserção de conteúdo ofensivo ou inapropriado. Isto é conseguido simplesmente "voltando" para uma versão anterior mais aceitável da página wiki por meio do recurso "histórico da página" wiki. Em um contexto de ensino, o desenvolvimento da página wiki é prudentemente deixado como esfera de atuação do grupo de estudantes. Qualquer diferencial de poder vertical ou divisão de status podem ser atenuados por intermédio do professor, que adota o papel de observador no processo criativo/destrutivo.

\section{Propriedade e pacto}

Quase não há dúvida de que os limites entre os profissionais e o público em geral estão sendo aos poucos erodidos pela proliferação e adoção ampliada de softwares interativos. Uma análise detalhada de sites de wikis sobre temas médicos ou legais confirmam isso. Em novas parcerias que estão sendo abertas, leigos e profissionais reúnem suas idéias, relações e negociações para criar locais de armazenamento de conhecimentos que transcendem os recursos tradicionais previamente disponíveis. Há uma espécie de "mentalidade coletiva" que emerge dessas interações virtuais, provavelmente revelada pela primeira vez por RHEINGOLD (1998) e outros. Os softwares coletivos, como wikis, folksonomias $^{5}$ e aplicativos compartilhados são simplesmente ferramentas que estão facilitando essa revolução social. Ultimamente, os profissionais estão começando a perceber que não são mais os árbitros de todo o conhecimento, mas que através do uso de tecnologias de informações e comunicações, todos podem contribuir dentro da "arquitetura de participação” (O’REILLY, 2004).

Alguns estudantes expressaram inquietação com o recurso que permite apagar ou modificar o "trabalho duro" anterior em vez da aceitação. Às vezes, eles mantêm a crença de que as idéias são "suas" que, de fato, em muitos casos, são mesmo. Elas o são até clicarem em "enviar"; a partir de então, o conteúdo torna-se "propriedade pública” e está sujeito a qualquer destruição. Já indicamos que o conflito pode ocorrer e observamos divergências entre nossos próprios estudantes durante a edição e elaboração de conteúdo de uma página wiki. Nesse contexto, a noção de propriedade intelectual tornase problemática, e a não ser que os membros do grupo de páginas wiki concordem com o conteúdo, uma série infindável de "guerras de modificações" pode se dar. Em geral, usuários de wikis percebem que o espaço de edição está aberto e livre para todos usarem e contribuírem e que o processo criativo/destrutivo continua sempre.

\section{Blogs e textos criativos}

Como muitos estudantes estão percebendo, escrever para a web nem sempre é o mais fácil. Webs logs, ou blogs, ganharam a forma de diários reflexivos online e são páginas encontradas na web, produzidas predominantemente por indivíduos, embora grupos e corporações também possam nelas estar envolvidos. Há também um recurso para leitores, freqüentemente os próprios blogueiros, que permite dialogar com quem escreveu o texto e gerar uma discussão durante um período de tempo.

Muitos blogueiros registram que escrever com regularidade no $b \log$ possibilita-lhes descobrirem um lado mais criativo de si próprios (NÜCKLES et al., 2004). Alguns declaram que escrever $b \log$ fez deles melhores escritores e, finalmente, melhores comunicadores (WILLIAMS et al., 2004). Escrever blog tem também um aspecto curiosamente viciante, principalmente se o blogueiro sabe que tem leitores. Os estudantes geralmente escrevem blogs sobre o que os afeta durante seus estudos, e ficam contentes com a oportunidade de compartilhar seus pensamentos com outros. Eles se alegram ao receberem comentários 
feitos pelos leitores, indicando assim que as anotações ali inseridas estão sendo lidas e valorizadas. Estar integrado a um sistema de busca interativo tagging [organizado com tags], como o Del.icio.us ou o Technorati, pode também aumentar o tráfego para um blog e, quando outros blogueiros entram por meio de links em seus sites, as listas dos blogs sobem nos rankings de "popularidade". Alguns blogueiros famosos já desfrutam de milhares de leitores constantes (WILLIAM et al., 2004; BOULOS et al., 2006).

Estimular os estudantes a criarem um blog de grupo, em que cada membro tem a responsabilidade de contribuir fazendo atualizações com regularidade, é um meio válido para engajar estudantes mais tímidos e um bom equalizador na tentativa de engajar todos os estudantes no aprendizado ativo e opinativo. As pesquisas indicam que diários escritos sobre o aprendizado podem alimentar um envolvimento cognitivo mais profundo com o conteúdo do curso (NÜCKLES et al., 2004) e estimular uma reflexão crítica (KUHN, 1991). Além disso, se mantido no contexto do aprendizado, o diálogo entre os blogueiros pode gerar envolvimentos ricos e significativos com o material do curso, com as experiências e as novas idéias (WILLIAMS et al., 2004).

\section{Mundo virtual e second lives}

Um mundo virtual é um ambiente multimídia simulado, hospedado no computador, usualmente desenvolvido em toda a Web, e destinado, assim, aos usuários que podem "habitá-lo" e interagir via suas auto-representações gráficas conhecidas como avatares. O site da Virtual Worls Review http://www.virtualworldsreview.com fornece uma lista útil de mundos virtuais com duas dimensões (2D) e tridimensionais (3D) que enfatizam a interação social e continuam online. Destes, Second Life < http://secondlife.com/ - Imagem $1>$ talvez seja o mais popular hoje e, em meados de fevereiro de 2007, registrou mais de 3,5 milhões de cidadãos virtuais ou "Lifers", todos com seus próprios avatares de alta resolução totalmente texturizados que podem ser adaptados com requinte conforme o gosto ou a necessidade do usuário. < http://www. virtualworldsreview.com/secondlife $>$.

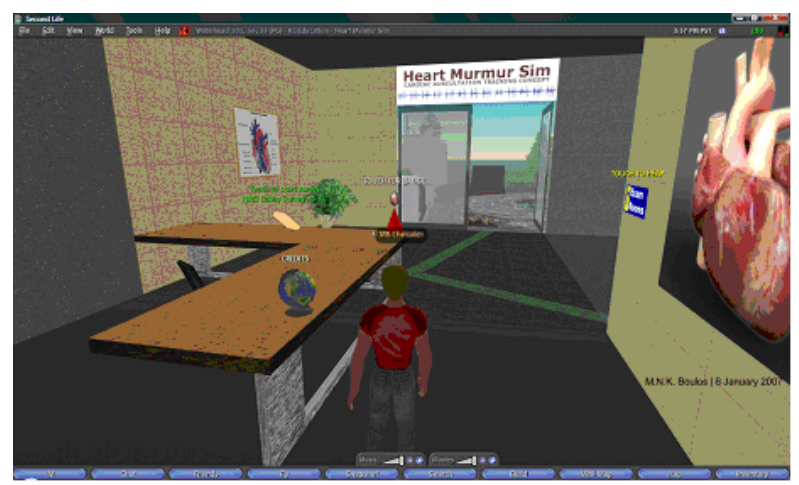

Imagem I - Tela extraída do mundo virtual educacional 'Heart Murmur Sim - Cardiac Auscultation Training Concept' [Simulação de som anormal do coração - Imagem de Treinamento de Ausculta Cardíaca] criado no Second Life, que permite aos visitantes (estudantes de medicina) dar uma volta em uma clínica virtual e testar suas habilidades de identificar diferentes tipos de sons anormais do coração, com base nos arquivos de som do estetoscópio virtual da Universidade McGill $<$ http://sprojects.mmi.mcgill.ca/mvs/mvsteth.htm $>$.
Mundos virtuais, como o Second Life, não são meros jogos 3D para vários jogadores. A experiência de imersão que esses ambientes oferecem combina muitas características da Web 2.0, como mensagens instantâneas, perfis, avaliações sobre os usuários e rede interativa, com uma única forma de interação online, que envolve compartilhar vários objetos e colaborações criativas na construção e funcionamento de lugares e serviços no mundo virtual (conteúdo gerado pelo usuário). Slurl $<$ http://slurl.com>, um serviço na Web, que permite vincular sites externos ou remetê-los para lugares do Second Life (escolhidos pelos usuários como favoritos) também estão se expandindo. Alguns especialistas financeiros vêem até oportunidades únicas de negócios e de publicidade no Second Life (por exemplo: < http://money.cnn. com/2006/1 1/09/technology/fastforward_secondlife.fortune/index.htm > e artigos do Financial Times: http://www. ft.com/cms/s/cf9b81c2-753a-1 ldb-aea 1-0000779e2340. html e http://www.ft.com/cms/s/3e2 la6ca-7a37-1 ldb8838-0000779e2340.html. O potencial de uma rica experiência como essa no ensino também só pode ser grande.

Em um mundo virtual, educadores podem criar comunidades em que os estudantes possam se registrar e interagir online. Dentro desses mundos virtuais educacionais, os estudantes usarão seu avatar para aprender novas tarefas e desenvolver estudos detalhados visíveis no mundo virtual < http://en.wikipedia.org/wiki/Virtual_world\#In_the_classroom $>$. Na verdade, o Second Life inclui uma seção ou comunidade orientada para o ensino, e várias instituições educacionais nos Estados Unidos já o utilizam (ver "Top 20 Educational Locations in Second Life" (com links que remetem para ele usando o Slurl):<http:// www.simteach.com/wiki/index.php?title $=$ Main_Page $>$.

Educause tem páginas dedicadas ao Second Life (por exemplo, http://connect.educause.edu/taxonomy/ term/2 174/0), que também foi foco de muitas atualizações de blogs educacionais recentes (por exemplo: http://stevewheeler.blogspot.com/search/label/Second\%20Life).

ANTONACCI et al. (2005) exploraram a natureza do Second Life em um texto online e apresentações de vídeo. Mais recentemente, YELLOWLEES et al. (2006) avaliaram o Second Life como uma ferramenta para o ensino de medicina destinado ao aprendizado sobre alucinações psicóticas, e concluíram que "o uso de ambiente gráficos conectados à internet possibilita o ensino público sobre doenças mentais".

Os resultados de uma pesquisa recente com duas mil pessoas (parte de um estudo de seis anos sobre atitudes

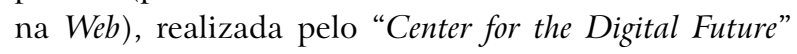
[Centro para o Futuro Digital], localizado nos Estados Unidos, constatou que muitos membros das comunidades online acreditam que as comunidades virtuais são tão importantes quanto suas contrapartidas do mundo real (BBC NEWS ONLINE, 2006). Portanto, os mundos virtuais $3 \mathrm{D}$ parecem oferecer muitas vantagens criativas adicionais para o ensino enquanto espaços interativos para aprendizado mas, como acontece com todos os aplicativos, é preciso tomar cuidado. 


\section{Principais desvantagens}

Apesar de o Second Life ter dois mundos ou duas grades separadas, uma para adolescentes e outra para adultos, e um conteúdo de grande utilidade gerado pelo usuário (por exemplo, http://orthodoxwiki.org/Virtual_Chapel), elementos indesejáveis, como jogos de azar/vício na internet, pornografia e exploração sexual de crianças (e adultos) online continuam a ser grandes problemas no Second Life. A mesma coisa acontece em muitos outros serviços da rede interativa Web 2.0 como no MySpace. Mesmo depois que um "lifer" desativa "Show/Search Mature Places and Events" no Second Life, ainda há uma grande possibilidade de encontrar um conteúdo ofensivo não-solicitado (TERDIMAN, 2006; REUTERS, 2007)

Outro defeito, menos importante, é a necessidade de uma conexão de internet banda-larga veloz e de um computador e uma placa de vídeo mais sofisticados para possibilitar que o software do Second Life que, deve ser instalado na máquina do usuário, funcione de maneira estável e se comunique em tempo real com os servidores do Second Life e outros lifers online no mundo virtual.

\section{Mashups e outros dispositivos}

A quantidade de softwares cada vez mais sofisticados que se tornou disponível para a comunidade conectada traz com eles a capacidade de destruir e recriar trabalhos de criação digitais previamente gerados. Conhecidos como "mashups", grande parte das imagens, dos sons e dos textos modificados, encontrados na Web 2.0, mantêm pouca ou nenhuma semelhança com suas formas iniciais. Esse replanejamento é uma característica comum crescente na Web 2.0. Um mashup extraordinário é uma combinação de recursos de mapas.

Serviços de mapas online, como o Google Maps (http://maps.google.com), permitem que os usuários naveguem pela maior parte do globo (mesmo à noite, no site http://moon.google.com/) por meio de uma interface da Web interativa, cuja visualização tem níveis variados de resolução, através de mapas, imagens de satélites ou de uma combinação dos dois. Mashups de mapas podem ser alimentados por dados de outras fontes daqueles mapas online, resultando em novos mapas interativos, gerados pelo usuário, que podem ter marcadores clicáveis para mostrar pontos de interesses específicos. Mashups de mapas podem até mostrar links para informações adicionais encontradas na Web sobre aqueles pontos (definição adaptada de: Educause. 7 things you should know about... Mapping Mashups [Sete coisas que você precisa saber sobre... Mashups de Mapas] em http://www.educause. edu/ir/library/pdf/ELI7016.pdf).

Uma vez que o RSS (Really Simple Syndication/Rich Site Summary) [Distribuição Realmente Simples/Sumário de Sites Interessantes] está se tornando cada vez mais usual como meio de publicação e compartilhamento de informações online, tem-se tornado crescentemente importante ampliá-lo para permitir que os lugares sejam descritos de uma maneira interoperável. Essa medida possibilita que os usuários solicitem, agreguem, compar- tilhem e mapeem geograficamente informações com tags (SCHUTZBERG, 2006). A alimentação sobre a gripe aviária pela Daden para o Google Maps é um exemplo prático de uma "geoalimentação" relacionada à saúde: <http:www.daden.co.uk/pages/000208.html>. Outro exemplo, o HEALTHmap (http://healthmap.org), um sistema de mapa de alerta da doença global, também se baseia no Google Maps e em notícias (Imagem 2).

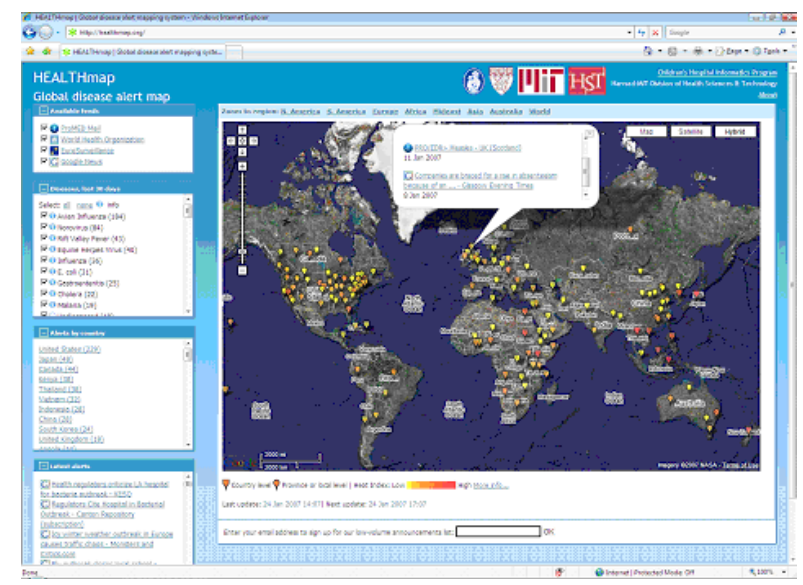

Imagem 2 - Tela extraída do HEALTHmap (http://healthmap.org), um serviço mashup de mapas, combinados com novos links, relacionados à saúde, de diversas fontes de mapas derivadas do Google Maps, usando a API (Application Programming Interface) [Interface de Programação de Aplicativos] que o Google Maps fornece com esse propósito. (http://www.google.com/apis/maps).

Além disso, com a cortesia de softwares grátis ou baratos como o GooPs (http://sites.onlinenw.com/goops/ goops.php) e o GpsGate (http://franson.com/gpsgate/), os usuários podem assinalar sua própria posição nos mesmos mapas e também ver a posição de seus amigos em tempo real na Web, se tiverem um simples GPS (um dispositivo baseado no Sistema de Posicionamento Global para identificar uma posição) como um receptor USB GPS ligado ao seu laptop ou PC.

Os que se entusiasmam com fotografias podem usar câmeras com GPSs embutidos para possibilitá-los colocar coordenadas do lugar exato na terra em cada fotografia foi tirada. No entanto, mesmo sem esses dispositivos as pessoas estão aptas a "geotag" suas fotos e a utilizar os serviços existentes na Web 2.0 como o Flickr (http://www. flickr.com/groups/mappr), o Mappr (http://www.mappr. com), e o Google Earth (http://earth.google.com) de muitas maneiras originais e entusiasmantes (TORRONEM, 2005).

Exemplos mais recentes de mashups de mapas incluem o Jotle, um Maps-Flickr do Google (fotos) com um Mashup do YouTube (vídeos): < http://www.jotle.com> e o "Google Books and Maps" (para um exemplo da geografia médica do último, ver a seção "Places mentioned in this book" [Lugares mencionados neste livro] em: <http://books. google.com/books?vid=ISBN159385 160X>.

Mashups de mapas são, assim, um excelente exemplo de informações (compartilhadas, reutilizadas e reconcebidas) remixadas na Web 2.0 para produzir conteúdo 
de valor-agregado. A distribuição global de ferramentas geoespaciais, imagens e mapas "grátis" pelo Google e outros provedores deve ser aplaudida como um passo significativo em direção à "wikificação" final de mapas e GIS ou Geographic Information Systems [Sistemas de Informações Geográficas] (BOULOS, 2005).

SYM-SMITH (2007) descreve como os conceitos de Web 2.0 e de computação interativa - em que a tecnologia põe o poder nas mãos das usuários e não das instituições - estão reescrevendo as regras na área de navegação pela terra. Educause publicou dois interessantes textos de duas páginas sobre o uso dos mashups de mapas (Educause. 7 things you should know about... Mapping Mashups [Sete coisas que você precisa saber sobre... Mashups de Mapas]: $<$ http://www.educause.edu/ir/library/pdf/ELI7016.pdf>) e Google Earth (Educause. 7 things you should know about... Google Earth [Sete coisas que você precisa saber sobre... Google Earth]: <http://www.educause.edu/ir/library/pdf/ ELI7019.pdf $>$ ) em educação e suas conseqüências para o ensino e o aprendizado. Mashups de mapas certamente têm um grande potencial para o ensino e alguns educadores já o utilizam (ver as páginas do Educause citadas acima).

Mashups de mapas oferecem muitas possibilidades para educadores criativos, mas essas possibilidades necessitarão ser identificadas, exploradas em vários contextos/ cenários, e cuidadosamente pesquisadas e avaliadas para documentar as melhores práticas antes de poderem ser usadas com segurança nas atividades diárias de ensino e aprendizado.

\section{Conclusão}

Neste curto artigo, mostramos que existem muitas oportunidades para os estudantes se engajarem em uma interação e em um aprendizado colaborativos por meio de softwares possibilitados pela Web 2.0. Compartilhar, combinar e misturar objetos digitais pode ser tanto criativo quanto destrutivo, mas geralmente levam a resultados mais positivos e acurados. Enfim, wikis, blogs, mashups, mundos virtuais 3D e outros aplicativos interativos podem criar para os estudantes um ambiente informal vibrante, dinâmico e desafiador onde aprender. Esses ambientes vão além dos limites tradicionais dos estabelecimentos de ensino, e atravessam áreas que ainda devem ser inteiramente exploradas, levantando questões interessantes a serem trabalhadas pelos professores. Uma coisa é certa - a popularidade dos softwares interativos na internet continuará a crescer, uma vez que mais usuários começam a explorar o potencial para gerarem suas próprias concepções e construir suas próprias experiências de aprendizado personalizadas.

\section{Notas}

1. Neste artigo, muitas palavras serão mantidas em inglês por terem sido assim consagradas e, portanto, mais conhecidas como tais pelos usuários da internet. Ao longo do texto, algumas são explicadas pelo autor. Quando isso não se der, um esclarecimento será feito entre colchetes ou em nota de rodapé. No caso da Web
2.0, embora não haja consenso, entre os estudiosos e críticos da área, sobre o que realmente a diferencia da rede anterior para ser tratada como segunda geração, é considerada uma plataforma em que softwares deixam de ser apenas programas instalados nos computadores e passam a se integrar na rede mundial, permitindo a troca de informações e a colaboração entre os usuários nas próprias páginas da internet. (N.T.)

2. Wikis são sites colaborativos que podem ser editados pelos que os acessam. Um dos mais conhecidos é o da Wikipedia <www.wikipedia.org>, enciclopédia mundial online, redigida em diversas línguas, constantemente atualizada por seus usuários colaboradores. (N.T.)

3. Ver a seção Blogs e textos criativos. (N.T.)

4. Tag, neste contexto, é uma palavra-chave utilizada pelo usuário da internet para identificar seus sites favoritos ou um tema relacionado ao conteúdo publicado e que ele deixa disponível para outros usuários. (N.T.)

5. Folksonomia é uma classificação gerada pelo usuário com palavras-chave ("tags") para facilitar a recuperação de informações encontradas na web e que pode ser visualizada por outros usuários que, por sua vez, podem criar sua própria classificação. (N.T.)

6. Apelido preferido dos cidadãos do Second Life. A palavra foi mantida em inglês porque o autor se refere ao Second Life norte-americano. No entanto, no Second Life Brasil, que surgiu no país há um mês, eles são chamados "residentes". (N.T.)

\section{Referências bibliográficas}

ANTONACCI, D. M.; MODARESS, N. Second Life: The Educational Possibilities of a Massively Multiplayer Virtual World (MMVW), 2005. Disponível em: http:// www2.kumc.edu/netlearning/SLEDUCAUSESW2005/ SLPresentationOutline.htm. Acesso em: 21 Jan, 2007.

BBC NEWS ONLINE. Virtual pals 'soar in importance'. 30 Nov. 2006. Disponível em: http://news.bbc. co.uk/1/hi/technology/6158935.stm. Acesso em: 24 Jan. 2007.

BELAWATI, T. The impact of online tutorials on course completion rates and student achievement. Learning, Media and Technology, v.30, n.1, p.15-25, 2005.

BOULOS, M. N. Web GIS in practice III: creating a simple interactive map of England's Strategic Health Authorities using Google Maps API, Google Earth KML, and MSN Virtual Earth Map Control. International Journal of Health Geographics, v.22, 2005. Disponível em: http://www.pubmedcentral.nih.gov/articlerender. fcgi? artid=1242244. Acesso em: 15 Feb. 2007.

BOULOS, M. N.; MARAMBA, I.; WHEELER, S. Wikis, blogs and podcasts: a new generation of Web-based tools for virtual collaborative clinical practice and education. BMC Medical Education, v.6, n.41, 2005. Disponível em: http://www.biomedcentral.com/1472-6920/6/41. Acesso em: 12 Feb. 2007 
CLARK, R. E. Media will never influence learning. Education Technology Research and Development, v. 42, n.2, p.21-29, 1994.

ENGESTRÖM, Y. Developmental studies of work as a test-bench of activity theory: the case of primary care medical practice. In: LAVE, J.; CHAIKLIN, S. (Eds.) Understanding Practice: perspectives on activity and context. Cambridge: Cambridge University Press. 1993.

GODWIN-JONES, R. Emerging Technologies: Blogs and Wikis: Environments for On-line Collaboration. Language Learning \& Technology, v.7, n.2, p.12-16, 2003.

JONASSEN, D. H.; PECK, K. L.; WILSON, B. G. Learning with Technology: a constructivist perspective. Upper Saddle River, NJ: Merrill. 1999.

KOZMA, R. B. Will media influence learning? Reframing the debate. Education Technology Research and Development, v.42, n.1, p.7-19, 1994.

KUHN, D. The Skills of Argument. Cambridge: Cambridge University Press. 1991.

NÜCKLES, M. et al. The use of public learning diaries in blended learning. Journal of Educational Media, v. 29 , n. 1, p.49-66, 2004

O'REILLY, T. Open Source Paradigm Shift. 2004. Disponível em: http://tim.oreilly.com/articles/paradigmshift_0504.html. Acesso em: 15 Feb. 2007.

PARKER, A. A study of variables that predict dropout from distance education. Cited in Levy, Y. (2007 in press) Comparing dropouts and persistence in e-learning courses. Computers \& Education, v.48, p.185-204, 1999.

PUTNAM, R. Bowling alone: The collapse and revival of american community. New York: Simon and Schuster, 2000 .

REUTERS. Second life: interpol launches task force on child sex abuse, 17 Jan. 2007. Disponível em: http://news. soft32.com/interpol-launches-task-force-on-child-sexabuse_3268.html. Acesso em: 2 Feb. 2007.

RHEINGOLD, H. The virtual community: homesteading on the virtual frontier. Boston Ma: MIT Press, 1998. Disponível em: http://www.rheingold.com/vc/book/. Acesso em: 14 Feb. 2007.

RICE, R. E. Media appropriateness: using social presence theory to compare traditional and new organisational media. Cited in STACEY, E. (2002) Social presence online: networking learners at a distance. In: WATSON, D; ANDERSON, J. (Eds.) Networking the learner: computers in education. Boston, MA: Kluwer Academic Press, 1993.

RICHARDSON, W. Blogs, wikis, podcasts and other powerful web tools for classrooms. Thousand Oaks, CA: Corwin Press, 2006.
SCHUTZBERG, A. Fun with GeoRSS. Directions Magazine. Disponível em: http://www.directionsmag. com/article.php?article_id $=2197 \&$ trv $=1$. Acesso em: 09 jun. 2006

SHORT, J.; WILLIAMS, E.; CHRISTIE, B, The social psychology of telecommunications. London: John Wiley and Sons, 1976.

SYM-SMITH, D. Navigation in 2007: it's much more than maps. Directions Magazine. Disponível em: http://www.directionsmag.com/article.php?article $\mathrm{id}=2379 \&$ trv $=1$. Acesso em: 24 Jan. 2007.

THORNE, S. Second language acquisition and the truth(s) about relativity. In: LANTOLF, J. (Ed.) Sociocultural theory and second language acquisition. Oxford: Oxford University Press, p.219-244, 2000.

TERDIMAN, D. Phoney kids, virtual sex. 12 Apr. 2006. Disponível em: http://news.com.com/Phony+kids, +vir tual+sex/2100-1043_3-6060132.html. Acesso em: 24 Jan. 2007.

SCHUTZBERG, A. Fun with GeoRSS. Directions Magazine. Disponível em: http://www.directionsmag. com/article.php?article_id $=2197 \& \operatorname{trv}=1$. Acesso em: 09 jun. 2006

TORRONE, P. How to GPS tag photos: flickr, mappr, google earth. 2005. Disponível em: http://www.makezine. com/blog/archive/2005/07/how_to_gps_tag.html. Acesso em: 10 Feb. 2007.

TU, C. The measurement of social presence in an online learning environment. International Journal of E-Learning, v. 1 n.2, p.34-45, 2002.

TUNG, F.W.; DENG, Y.S. Designing Social Presence in e-Learning Environments. Testing the effect of interactivity on children. Interactive Learning Environments, v. 14, n.3, p.251-264, 2006.

WALLACE, P. The psychology of the internet. Cambridge: Cambridge University Press, 1999.

WHEELER, S. Learner support needs in online problem based learning. Quarterly Review of Distance Education, v.7, n.2, p.175-184, 2006.

WILLIAMS, J. B.; JACOBS, J. Exploring the use of blogs as learning spaces in the higher education sector. Australian Journal of Educational Technology, v.20, n.2, p.232-247, 2004. Disponível em: http://www. ascilite.org.au/ajet/ajet20/williams.html. Acesso em: 14 Feb. 2007.

YELLOWLEES, P. M.; COOK, J. N. Education about hallucinations using an internet virtual reality system: A qualitative survey. Academic Psychiatry, v.30, n.6, p.534-539, 2006. 


\section{Sobre os autores}

\section{Steve Wheeler}

Professor em Educação e ICT na Faculdade de Educação da University of Plymouth. Desde 1976 trabalhou com mídia educacional e tecnologia além de ter sido consultor em diversos projetos inovadores de e-learning, incluindo o projeto RATIO no Reino Unido e, a rede de banda larga ampla do estado de Dakota do Sul nos Estados Unidos. Ele é professor visitante de várias universidades nos Estados Unidos e na República Tcheca e é regularmente convidado como palestrante em diversas conferências internacionais. Seus interesses de pesquisa incluem percepção de aprendizado e e-learning. Além disso, é membro do conselho editorial de seis revistas acadêmicas, incluindo ALT-J, Interactive Learning Environments e IRRODL. Sua publicação mais recente é o 'Transforming Primary ICT', ainda sem tradução para o português.

\section{Maged N. Kamel Boulos}

Professor em Informática da Saúde na University of Plymouth na cidade de Devon no Reino Unido. Antes exerceu o mesmo cargo na University of Bath no Reino Unido, e na City University em Londres, ambas também no Reino Unido. Além de sua graduação em medicina e mestrado em dermatologia, ainda tem um mestrado em "Medical Informatics" do King's College, University of London, Reino Unido, e doutorado em "Measurement and Information in Medicine" na City University, em Londres. Já publicou muitos livros sobre Web 2.0/software social, a Web Semântica (Semantic Web) e o sistema de informação geográfica, incluindo Internet/Web GIS, em saúde e cuidado à saúde. Também é Editor Chefe do Open Access International Journal of Health Geographics http://www.ij-healthgeographics.com, e um dos principais pesquisadores do projeto de e-saúde CAALYX EU FP6 http://caalyx.eu. 